\title{
Photons do not lie
}

\author{
The true value of history.
}

\section{Euan Nisbet}

The camera sweeps down the majestic garden approach, the marvellous avenue of intertwined rose-chrysanthemum trees. Cranes flock above. Skittering impalas graze amid bamboo-gums, in which koalas and lumbering pandas loll under the warm sun. Onwards we glide to the palace and into the grand throne room, thronged with a vast crowd, the notables of Earth. They rise. In Reykjavik, the Nobel ceremony has begun. Entering in state to the ancient imperial anthem, Rock Around the Clock, is Her Majesty, Queen Hillary IV.

The laureates are led in. What paragons they are! There had been criticism that the biology prize should be discontinued, as biology is so unchallenging. That was surely correct for stampcollecting physics, but who cannot applaud this year's biology winner, recreator of the rabbitsized, slipper-and-iPub-fetching housetrained woolly mammoth? No maths prize, after that laureate's affair with the Prince Consort. How dare she! Of course, the discovery of the soul led to calls for reinstatement, but the Godel-Ishodad of Merv-Epimenides theory shows that, although detectable, that 'brane cannot be investigated, frangible yet intangible. The quest is abandoned.

The heavyweight prizewinners come on. Geology - for the discovery of the tenth inhabited planet, this one orbiting Aldebaran. The inhabitants are aggressive ant-like beings in the throes of nuclear war, but no doubt they will see reason when we pacify them. Such a pity that we had to sterilize all the humanoids of the eighth planet: the peace prize goes to the Admiral of that expedition, for those eloquent words of consolation, after the ritual welcoming dance offered by the inhabitants accidentally unveiled one of the Admiral's men. The strong reaction was of course fully justified.

Next is the economics prize. As is customary, this goes to the ranking associate professor at Lunar Chicago University, whose 'great idea' was the reinvention of crime. It is now proven that economic systems are unstable unless criminals flourish. Old fogies decry this, but the huge 'Make
Crime Real' demo outside the palace has much sympathy. Several provinces now select lucky teenagers for training, providing necessities such as body piercings, drugs and 'attitude.'

A hum of excitement pervades the room. It is time for the Sacred Reminder. The prime minister rises to recount the saving of humanity. Suddenly, rudely, there is a slight buzz. A masculinist suf-

travel to anywhere in the cosmos.

Last comes the greatest prize. What is more valuable than history, recovery of our lost past? The flare frizzled the databases, leaving only tiny fragments of our culture in the personal oddments of scientists in Lunar City: the deficient aesthetic of Bach, Mozart, Shakespeare, Milton, Keats - Jane Austen, for goodness' sake. But now we unearth a marvellous treasure trove. Of course even the geeks loved Elvis and Abba, but only now do we fully realize just how limited was their vision, they who did not even value the great Sinatran song of creation: "Do BEl Do BE! DO?"

Now we are recovering the true genius of the Golden Age. Here is our history prizewinner now, rising to deliver her lecture. She recounts the long hours spent cruising round the wavefront, laboriously integrating photon after photon on the sphere 200 light years out, asshe collected the

frager has managed to enter. He is quickly ejected, burka fluttering. The prime minister dryly observes that the formula limiting men to $10 \%$ of academic posts is already over-generous.

The Reminder begins: the sterilization of Earth in 2020 by the week-long Great Solar Flare. She recounts the wondrous chance that the US president was on lunar darkside, in Lunar City to celebrate the close of her third term, accompanied by the Chinese president, the British Crown Prince and the Crown Princess of Japan. The presidents' energy and constitutional wisdom inspired extraordinary efforts to make the colony viable, and then rebuild. Then came the romance between Prince and Princess, and the final emotional abdication of the Dual Presidency, with constitutional dispensation of our Empire of Luna and Three Planets, into the hands of their beloved adopted heirs.

Since then, what progress there has been under the Rose and Chrysanthemum! From bones and buried seeds we have recovered the biosphere, even raising Earth's population to more than a million. Mirrored Venus was terraformed; Mars warmed by chlorofluorocarbons, and methane from polar peat bogs. The end of physics came with the discovery of CUTE, the canonic universal theory of everything, bringing instantaneous radio broadcasts of the twentieth century.

What diamonds she has found! One is the 00.48 a.m. BBC shipping forecast, a mysterious sacred compline into the dead of night, with its great unsung hymn of 'Sailing by' into the afterlife. From American radio, the account by Orson Welles of the 1938 martian attack on Earth is previously known only in a corrupt fake purporting to have been written by a Mr H.G. Wells. Already major funding supports archaeologists searching Mars for the extinct civilizations under our new oceans.

Finally comes the climax of her Nobel lecture. Technically, it is far easier to recover radio than TV. But now, a visual revelation - proof that twentieth century humanity was in touch with alien life elsewhere in the Universe! Praise be: these aliens, delegated to each nation but unknown to us moderns, are fully humanoid, female of course, possessing unearthly beauty and uttering truly sublime speeches for World Peace. Here is the highest glory of the Age of Gold. Here from civilization's ancient heartland Perth, Western Australia - gentlemen and noble ladies, I give you the Miss Universe competition, 1979!

Euan Nisbet puzzles over Archaean rocks and monitors atmospheric greenhouse gases at Royal Holloway, University of London, Egham, UK. 